\title{
Socio-hydrology: an interplay of design and self-organization in a multilevel world
}

\author{
$\underline{\text { David J. Yu }}^{1,2,3}, \underline{\text { Heejun Chang }}^{4}, \underline{\text { Taylor T. Davis }}{ }^{3,5}, \underline{\text { Vicken Hillis }}^{6}, \underline{\text { Landon T. Marston }}^{7}, \underline{\text { Woi Sok Oh }}^{8}, \underline{\text { Murugesu Sivapalan }}^{9,10}$ \\ and Timothy M. Waring $^{11}$
}

\begin{abstract}
The emerging field of socio-hydrology is a special case of social-ecological systems research that focuses on coupled human-water systems, exploring how the hydrologic cycle and human cultural traits coevolve and how such coevolutions lead to phenomena of relevance to water security and sustainability. As such, most problems tackled by socio-hydrology involve some aspects of engineering design, such as large-scale water infrastructure, and self-organization in a broad context, such as cultural change at the population level and the hydrologic shift at the river basin or aquifer level. However, within the field of socio-hydrology, it has been difficult to find general theories that assist our understanding of the dynamics emerging from the interplay between design and selforganization, hindering generalization of phenomena between cases. We address this gap by developing insights on how the theoretical frameworks of robustness-fragility trade-off and cultural multilevel selection can inform our understanding in this regard. We apply the two theories to two cases in the Ganges Brahmaputra Delta in Bangladesh and the Kissimmee River Basin in Florida, illustrating how the two theories may provide general insights into causal mechanisms shaping the socio-hydrological phenomena observed in the two cases. Specifically, we use the two theories to address (1) the transference of system fragility across different domains due to design choices and (2) the multilevel social processes in the nested organizational hierarchy that lead to the formation or collapse of shared cultural traits. We show that these two theories, separately or taken together, can provide richer theoretical grounding for understanding socio-hydrological phenomena.
\end{abstract}

Key Words: coupled human-water system; cultural evolution; cultural multilevel selection; robustness; robustness-fragility trade-offs; sociohydrology; the levee effect

\section{INTRODUCTION}

The continued surge of interdisciplinary systems approaches to studying environmental and sustainability problems, notably the resilience of social-ecological systems, has highlighted the importance of viewing nature and society as interdependent systems and the tight feedback that connects them (Folke 2016). A similar systems approach, socio-hydrology or coupled humanwater systems, has only recently emerged within the discipline of hydrology and water resources, driven by a growing appreciation that many of the serious, recurring problems in water resources use originate from the lack of consideration of the two-way feedback between hydrologic and social systems (Sivapalan et al. 2012). Socio-hydrology is a rapidly growing research area, with a potential to push the field of hydrology beyond its traditional boundaries of focusing solely on hydrologic systems and processes (Konar et al. 2019). A core question in socio-hydrology is whether common phenomena can be identified in disparate cases and how they may be explained by the two-way feedback, thus creating general insights that transcend specific instances (Troy et al. 2015, Di Baldassarre et al. 2019). Several studies explored such phenomena, including trade-offs between short- and long-term flood vulnerabilities (Di Baldassarre et al. 2013, Merz et al. 2015), the shifting of societal preference about water allocation from economic production to environmental conservation (Van Emmerik et al. 2014, Chen et al. 2016), unintended consequences of improving irrigation efficiency (Scott 2011, Grafton et al.
2018), urban water supply issues in less developed regions (Srinivasan 2015), and unintended consequences from the expansion of and over-reliance on water reservoirs (Di Baldassarre et al. 2018).

While building on social-ecology, socio-hydrology studies tend to be differentiated by three distinct features. First, the spatial and time scales of analysis are often at the levels where changes in the hydrologic cycle can be observed and examined. For example, regional spatial extents such as watersheds, river basins, aquifers, and citywide water supply networks are analyzed over a relatively long time scale to track changes in the hydrologic cycle (Zhang et al. 2014, Gunderson et al. 2017). Second, on par with emphasis on the evolution of hydrologic cycle, the field is interested in the evolution of human cultural traits, e.g., social norms, practices, etc., concerning water and the mechanisms and conditioning factors behind it (Sanderson et al. 2017, Roobavannan et al. 2018). Third, the role of built infrastructure is often explicitly recognized and included in analysis, especially the effects of infrastructure design on the trajectories of human-water interactions (Di Baldassarre et al. 2013, Yu et al. 2015, 2017). Given these features, a systems approach to studying socio-hydrology requires a consideration of how the interplay between design (infrastructure or policy design) and self-organization (hydrological shifts or social change) and generates emergent dynamics. Further, coupled human-water systems tend to contain multiple social

\footnotetext{
${ }^{1}$ Lyles School of Civil Engineering, Purdue University, ${ }^{2}$ Department of Political Science, Purdue University, ${ }^{3}$ Center for the Environment, Purdue University, ${ }^{4}$ Geography Department, Portland State University, ${ }^{5}$ Department of Philosophy, Purdue University, ${ }^{6}$ Human-Environment Systems, Boise State University, ${ }^{7}$ Department of Civil and Environmental Engineering, Virginia Tech, ${ }^{8}$ Department of Agricultural and Biological Engineering, University of Florida, ${ }^{9}$ Department of Civil and Environmental Engineering, University of Illinois at Urbana-Champaign, ${ }^{10}$ Department of Geography and Geographic Information Science, University of Illinois at Urbana-Champaign, ${ }^{11}$ School of Economics, Mitchell Center for Sustainability Solutions, University of Maine
} 
units embedded in a nested hierarchy (Gunderson et al. 2017). For example, smallholder households are embedded within irrigation communities, which are embedded within the jurisdictional hierarchies of local, regional, and federal level organizations. Given this multilevel nature, socio-hydrology also requires understanding of how multilevel dynamics in social organizations shape outcomes. It is, therefore, useful to think of coupled human-water systems are part designed and part selforganized systems. In other words, infrastructure or policy designs may be imposed to achieve particular goals, but actual outcomes depend on how the hydrologic cycle shifts or how social processes within and between levels in a nested hierarchy evolve in response to such designs, often in unexpected ways.

However, general insights into the causal mechanisms affecting the interplay between design and self-organization and the multilevel nature of social change have been elusive in the field of socio-hydrology. Such insights are critical for improving understanding of how and why coupled human-water systems coevolve along certain trajectories and why they can be sustainable in certain cases and not others. We, therefore, aim to examine how coevolutionary patterns of socio-hydrology can be examined and linked by applying an overarching theoretical framework. Specifically, we draw on the theories of robustnessfragility trade-off (RFTO) and cultural multilevel selection (CMLS), two independent approaches that are, together, useful for understanding a wide range of dynamics exhibited by part designed and part self-organized systems. The theory of RFTO, arising from the social-ecological systems literature and control theory, presents generalizable insights about how system design altered to enhance robustness in one domain may lead to amplified fragilities in other ways (Csete and Doyle 2002, Anderies 2015). The theory of CMLS, arising from anthropology and sustainability science, explains the cultural change of human societies by identifying cultural transmission and selection processes operating at different levels of organizational hierarchy, and the consequences of these multilevel selection pressures on cultural trait emergence and persistence (Boyd and Richerson 1985, Waring et al. 2015). To illustrate the utility of these two theoretical lenses, we apply them to socio-hydrological phenomena observed in two case areas: community-managed flood protection systems (polders) in southwest Bangladesh and the Kissimmee River Basin, Florida.

We examine how the theoretical lenses of RFTO and CMLS can facilitate generalization by applying them to the phenomena of "levee effect" (White 1945, Montz and Tobin 2008) and "pendulum swing" (Kandasamy et al. 2014), two iconic patterns of socio-hydrology. The levee effect has been the subject of multiple socio-hydrology studies (Di Baldassarre et al. 2013, Viglione et al. 2014, Yu et al. 2017, Sung et al. 2018). According to the levee effect, building higher levees ultimately increases vulnerability to flooding in long run, rather than decreasing it, because short-term stability created by building levees can lead to expansion of practices that increase the costs and risks of rarer long-term disasters. The opposite of the levee effect is referred to as the adaptation effect, which means that allowing moderate exposure to flood events can lead to enhanced social capacity to cope with rare flood disasters in long run (Di Baldassarre et al. 2015). In summary, both effects involve trade-offs in system fragility between two levels of time scale (frequent vs. rare) and that these trade-offs arise because of the effects of design choices (infrastructure or policy designs) on the self-organization of flood memory, human settlement pattern, or flood hydrology.

The phenomenon of "pendulum swing" has been also studied by multiple socio-hydrology studies (Elshafei et al. 2014, Van Emmerik et al. 2014, Mostert 2018). This phenomenon pertains to the shifting of people's collective preference for allocation of water resources from economic development to environmental health. The current socio-hydrology literature provides only a mechanistic description of the phenomenon at the population level. For example, it relies on metaphors such as collective memory and community sensitivity, which identify a society's shared memory, attitude, or preference toward certain hydrological or environmental conditions. The basic idea is that the state of collective memory or community sensitivity is affected by hydrological events, e.g., flooding, which in turn feeds back to affect hydrology via a social response, e.g., construction of more levees, leading to altered hydrological processes in the future. Although simple and straightforward, these are "lumped" concepts that abstract away much of the underlying causal mechanisms of social change. In other words, there is a need to account for how a cultural trait may spread and become widely shared in a society despite diverse traits that may have initially existed at the level of individuals and how such shared norms may become stabilized or collapse and be overtaken by another cultural trait.

Producing general insights about multiple socio-hydrological phenomena would thereby require theories that address (1) tradeoffs in system fragility that arise as a result of design choices and the self-organized response of social or hydrological components, and (2) multilevel analysis covering both individual-level cultural variation and selection and population-level cultural dynamics. RFTO and CMLS, two theoretical approaches that are increasingly being used in sustainability studies (Reyes-García et al. 2016, Ishtiaque et al. 2017, Brooks et al. 2018, Ellis et al. 2018, Tellman et al. 2018), can meet these respective requirements, suggesting the benefits of these theories for addressing sociohydrological phenomena. Both separately and taken together, we argue that these two theories bring social science richness into the socio-hydrology literature, one that has historically been dominated by physical science and engineering perspectives.

\section{ROBUSTNESS-FRAGILITY TRADE-OFF}

According to RFTO, structural modification or fine-tuning of control of complex feedback systems to increase its robustness to one set of disturbances necessarily leads to increased fragilities to disturbances outside that set (Anderies 2015). Such trade-offs in robustness, or conversely, fragility, is a fundamental property of feedback systems (Bode 1945), and has been labeled the "conservation of fragility" elsewhere (Csete and Doyle 2002). The basic insight is that efforts to enhance robustness often serve merely to move fragilities around to different domains, rather than eliminating them. Such trade-offs are dangerous because people tend to develop a false sense of security, as emergent fragilities from altering system design are often hidden, and revealed only through catastrophic failures (Anderies 2015). RFTOs have been illustrated in a wide range of controlled systems, from linear feedback systems to complex engineered systems and socialecological systems. Within the social-ecological systems literature, 
Fig. 1. A typology of robustness-fragility trade-off (RFTO). (A) Structural RFTO represents a direct modification to a resource system structure, e.g., the construction of levees, dams, or irrigation canals, to reduce variability in a system output, e.g., water availability, flood risk, etc. (B) Network RFTO: two "source" resource systems whose outputs or benefit flows do not co-vary under a disturbance and a "sink" consumer system are connected through an exchange network. This exchange network reduces variability in the combined benefit flows to the sink system. (C) Feedback RFTO represents an insertion of feedback responses, e.g., control actions guided by pre-existing policies, to variations in a system state to achieve stability. (D) Structural and feedback RFTO combines structural RFTO and feedback RFTO, i.e., system structure is modified, and feedback responses are generated simultaneously. Adapted from Anderies (2015).

A
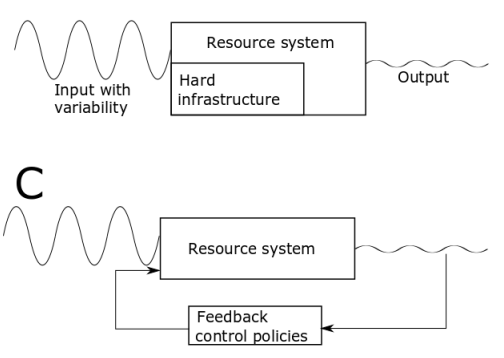

B

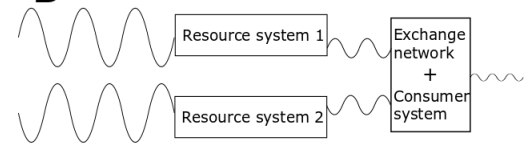

$\mathrm{D}$

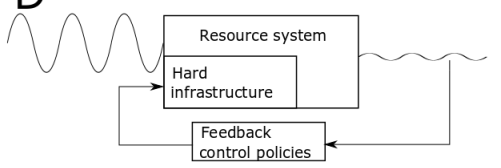

RFTO theory has been applied primarily to understand how human efforts to cope with environmental variability through the use of built infrastructures, policy actions, or both lead to the shifting of fragility across different scales or levels within a scale (e.g., Ishtiaque et al. 2017, Tellman et al. 2018). RFTO theory has also been discussed in a socio-hydrology context in a recent study (Yu et al. 2017). This study characterized the levee effect as an example of RFTO-induced phenomena by exposing hidden social problems that emerge because of building more flood infrastructure. A typology of RFTO (Fig. 1) has been proposed to help conceptualize how such trade-offs occur in a socialecological system context (Anderies 2015). Four basic types of RFTOs can exist according to this typology: structural RFTO, network RFTO, feedback RFTO, and feedback and structural RFTO. Structural RFTO represents a direct modification to the system structure, e.g., converting a natural floodplain to a semiengineered environment by the construction of levees (Fig. 1A). Such modifications help to suppress short-term environmental variability, e.g., daily tidal inundation, but also tend to be associated with increased fragilities at a different level of the time scale, such as catastrophic outcomes when a 500-year flood occurs, or on altogether different scale, such as free-riding behaviors of people regarding infrastructure maintenance. By contrast, network RFTO represents an insertion of an exchange network among multiple "source" systems, whose outputs or benefit flows respond differently (or do not co-vary in time) to a disturbance, and a "sink" system that taps into these benefit flows. Such an exchange network helps to reduce the effects of shortterm fluctuations in the source side on the sink side because of an insurance effect, i.e., even if one of the source systems cannot withstand a disturbance and fails to perform, other source systems that have the same function may withstand it and still allow the sink system to receive benefit flows (Fig. 1B). However, the connection to the larger network and the resultant interdependencies (where outputs of one node become inputs to another node) may exacerbate the risk of cascading failures triggered by a node failure in the network.

Feedback RFTO represents an introduction of feedback "control" response to variations in a system state to achieve stability (Fig. 1C). Such feedback controls are often dictated by some existing management policy or regulatory protocols. For example, dam or reservoir operations can be guided by preexisting operation rules that have been based on historical streamflow trends. However, when the streamflow pattern deviates significantly from the historical trend, conforming to these existing operation rules might worsen outcomes. Finally, structural and feedback RFTO occurs when both infrastructure modification, e.g., altering the design of flood protection infrastructure, and feedback control, e.g., dynamically adjusting reservoir water levels, occur to achieve stability (Fig. 1D). This form of system control is extremely powerful, and the system appears to be highly robust because of the combined effects of engineering design and feedback-driven regulatory control. However, it is also the most problematic because fragilities are hidden by the very power of structural changes and feedback controls and are revealed only because of rare catastrophic failures. Self-organization is behind the manifestation of most of these fragilities: from development of a false sense of security among people and the resulting shifts in their collective memory and land use patterns, to gradual shifts in natural system states and processes.

Finally, readers should note that RFTO originated from robust control theory, and the proofs and classical examples of this theory are focused on the time domain, i.e., how tight control of variability at some time frequencies lead to fragilities at other 
frequencies (Csete and Doyle 2002, Martins et al. 2005). However, it is important to note that such fragilities can show up in a different domain instead of a different time frequency. In the context of water systems, what characteristics of the system lead to fragilities emerging in a different domain as opposed to a different frequency? We suggest that fragilities can show up in a different domain when two domains are colocated or connected physically without obvious linkages to human eyes. The case of surface water irrigation in the Goulburn-Broken Catchment in Australia causing the issues of groundwater table rise, soil salinization, and degraded downstream water quality is a relevant example (Walker and Salt 2006). This is a case of fragility tradeoff between two domains: water quantity domain (irrigation to address fragility to variability in precipitation) and water-related quality domain (emergence of soil salinization and water quality issues). Groundwater and surface water systems are hydrologically connected in the region but the visibility of this linkage was low when the early settlers started to develop the area for farming. In comparison, fragility trade-offs between two frequencies seem to be more associated with societal selforganization, i.e., people adapt their activities to stability conditions (short-term stability) created in one level of time domain through structural modification or regulatory feedbacks. An example is the severe flood loss that happened in Brisbane, Australia in 2013 after multiple years of drought. Before the drought, the reservoirs in Brisbane were operated mainly for flood control purposes. However, adaptation to the drought, e.g., more water storage in the reservoirs and thus less room for flood storage, made the system more fragile to flooding when a wetter period followed immediately after the years of drought (Di Baldassarre et al. 2017).

\section{CULTURAL EVOLUTION AND CULTURAL MULTILEVEL SELECTION}

Social change, or shifts in the frequencies of cultural traits within populations, is an integral part of socio-hydrology, and is regarded as endogenous to coupled human-water systems dynamics (Sivapalan et al. 2012, Montanari et al. 2013). The question of how to theorize and model social change, and its twoway connection with hydrological processes, has garnered much interest and debate recently among hydrologists and water resources researchers (Gober and Wheater 2015, Loucks 2015, $\mathrm{Yu}$ et al. 2017, Roobavannan et al. 2018). We argue that the broader theory of cultural evolution and cultural multilevel selection (Boyd and Richerson 1985, Brooks et al. 2018) already provides excellent conceptual tools for understanding social change in this regard.

According to the dual-inheritance theory of cultural evolution (Richerson and Boyd 2004), individuals inherit traits culturally, through social learning, in addition to genetically, through reproduction. This cultural form of inheritance then gives rises to a distinct, nongenetic process of Darwinian selection (cultural selection), which can be modeled according to the same principles that biologists use to track relative frequencies among genetic traits over time. In this approach, cultural traits are defined as information, values, skills, or practices that individuals acquire specifically through social learning. And just as functional complexity accumulates over time among genetically inherited traits, so too does it accumulate in cultural traits, as we see in the accumulation of knowledge in science and technology, and in the complexity of social rules, norms, and practices involved in the management and use of natural resources (e.g., Ostrom 1990). Understanding the dynamics of cultural evolution is important to socio-hydrology because cultural traits strongly shape human interactions both with one another and with the environment and thus outcomes of human-water interactions in long run. One way or another, any theory capable of tracking and explaining social change will have to address underlying cultural processes that give rise to regularities in cultural traits among individuals.

Cultural selection, the cultural equivalent of Darwinian natural selection, occurs when a particular cultural trait is transmitted in a population at the expense of others because of its effect on individuals who use it in a given context (Mesoudi et al. 2006). For example, an individually-costly water conservation practice, like converting a lawn to a xeriscape, may be selected and persist in a society either because of formal incentives and regulations, or because of informal sanctions of peer pressure, reputation, and social comparison, or because individuals have personally internalized norms of conservation. But whatever the nature of the particular cultural selection pressures involved, they will depend on the particular cultural context, or the contingent history of shared beliefs and values that either promote or discourage the uptake of various practices. Thus, for example, when pre-existing rules and norms in a city favor structural measures of flood protection, an alternative norm for nonstructural forms of flood protection cannot easily invade and spread.

As these examples suggest, cultural traits can be transmitted vertically across generations, as children inherit the culture of their genetic parents, as well as horizontally, among peers of the same age or generation (Fig. 2A). In cases of horizontal transmission, learning strategies include conformist learning biases, in which individuals disproportionately copy the majority behavior, and success-biased learning, in which individuals preferentially copy other successful individuals. A shared cultural trait is formed when such learning strategies used by numerous individuals give rise to regularities in social rules, beliefs, values, or practices in a social group. Once established, a cultural trait can be further reinforced and stabilized through social effects such as peer pressure and group selection (Fig. 2C; Chudek et al. 2013). Alternatively, perturbations such as innovations, or cultural mutations, may disrupt an existing equilibrium (Fig. 2B). The theory of cultural evolution, therefore, provides a powerful set of ideas explaining both the emergence and stability of cultural traits over time, including those that influence the use and management of water resources.

It is critical to note that cultural selection can occur at multiple levels of the social organization (Richerson et al. 2016). Just as cultural traits can spread among individuals via social learning, so can they spread among groups of individuals, if the dominant level of selection is at the group level. This process of cultural selection at multiple levels is termed cultural multilevel selection (CMLS; Wilson and Kniffin 1999, Wilson et al. 2013). Waring et al. (2015) recently applied CMLS to social-ecological systems in the context of collective action problems in order to study the evolution of cooperative cultural traits within social groups. The force of cultural selection on a focal cultural trait can vary across different levels of social organization (individual vs. group; 
Fig. 2. (a) Diverse cultural traits (norms A, B, and C) can exist at the level of individuals and the proportions of these traits within a social group can change over time through the processes of cultural evolution in the forms of horizontal and vertical transmissions. (b) A cultural trait (norm C) is initially dominant and remains stable, resisting invasion by a mutant trait (norm A). (c) A cultural trait (norm C) is initially dominant but is unstable, being overrun by a mutant trait (norm A).
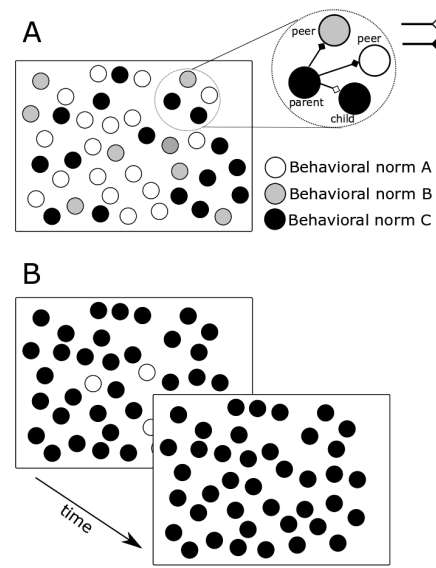

Norm $C$ is initially dominant and resistant to invasion by norm $A$. Norm A cannot spread and is weeded through cultural evolutionary processes.

$\longrightarrow$ Vertical transmission across generation Horizontal transmission among peers

The left panel shows a well-mixed population of agents with norms $A, B$, and $C$ at a point in time. The magnified part shows cultural transmission or evolutionary processes (vertical \& horizontal) in action.

C

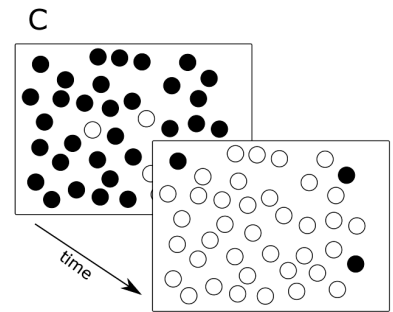

Norm $C$ is initially dominant but susceptible to invasion by norm $A$. Nusceptible to invasion by norm A. Norm A spreads and takes over as
the new dominant norm through cultural evolutionary processes.

Richerson et al. 2016). For example, a water conservation norm might replace a wasteful norm to achieve the common goal of water sustainability, if groups who adopt water conservation are more successful than those that do not. Whether or not this occurs, however, likely depends on the level of the social organization scale at which cultural selection is the strongest (Fig. 3). When water is abundant, and thus enforcement is weak, cultural selection would be dominant at the level of individuals and collective action for voluntary water conservation would likely fail. However, when water is scarce, water rates are high, and the government provides financial incentives to groups that achieve higher water conservation, cultural selection would be dominant at the group level, i.e., group selection. In this scenario, a groupbenefiting cultural trait would proliferate through mechanisms such as peer pressure and group competition. In reality, selection pressures occur at multiple levels in several connected social groups: an individualistic trait may prevail in some groups because of their unique physical or social context, while individuals in other groups may be driven more by peer pressure and group competition and adopt a group-benefiting trait.

\section{POLDERS IN SOUTHWEST BANGLADESH}

Hydrological variability and associated events such as riverine flooding adversely impact human livelihood. Thus, in many human-flood systems, build infrastructures such as levees and upstream dams are constructed to contain and smooth out hydrological variability. As a result, the frequency of flooding is dramatically reduced, existing development and production activities on vulnerable areas are better protected, and hydrological dynamics are largely unnoticed by people. However, these may lead to long-term changes that increase both total exposure to damages and vulnerability to flooding. Total exposure to damages is increased because enhanced physical protection often encourages greater development and economic activities on vulnerable areas (Di Baldassarre et al. 2013). That is, while levee construction does reduce the annual risk of flooding, the rise in development may outpace the reduction in risk and ultimately increases the total exposure to damages and thus expected damages from rarer flood events (Georgic 2019). At the same time, each flood that is contained by the protective infrastructures is a loss of opportunity for social learning of flood hazards. The absence of people's earlier exposure to such actual flooding experiences and learning opportunities may lead to a serious reduction, or loss, of local flood response capacity to be able to cope effectively with rarer flood events (Liao 2012, Yu et al. 2017). This phenomenon, referred to as the levee effect (White 1945, Tobin 1995), is increasingly being observed worldwide (Di Baldassarre et al. 2015). Here, we use the case of polders in southwest Bangladesh to illustrate how RFTO and CMLS can be used to interpret the levee and adaptation effects.

Fig. 3. An illustration of the cultural multilevel selection (CMLS) framework. Cultural selection can occur at multiple levels (individual, group, or both). When cultural selection is stronger at the group level, a group-benefiting cultural trait proliferates. When selection is stronger at the individual level, an individualistic trait is favored and spreads. Adapted from Waring et al. (2015).

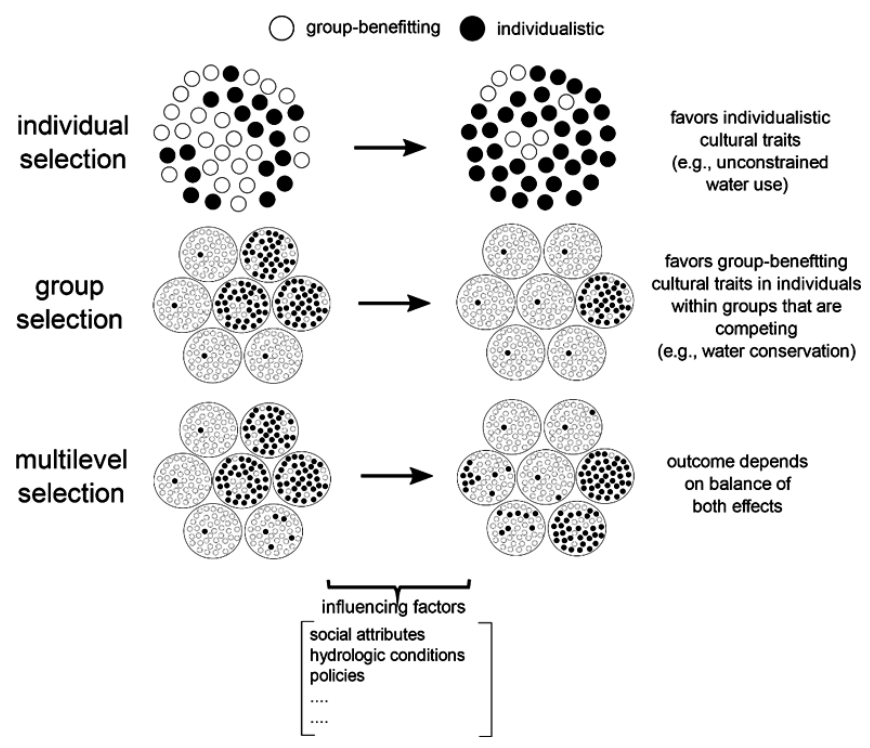

Before proceeding further, however, we would like to direct readers' attention to the other side of the levee effect. It is that the construction of levees has potentially strong positive effects through better protection of existing development and inducement of further development and production activities in floodplains (Stavins and Jaffe 1990, Ishtiaque et al. 2017, Georgic 2019, Hutton et al. 2019). This likely means creation of greater 
wealth and social benefits that would not exist at all in the levee's absence. At the same time, these positive effects likely endow individuals and groups with greater financial capacity to withstand a major flood event with smaller long-term consequences than they would have in the absence of levees and with the knowledge and practice of habitual flood resilience. In this view, it makes sense to speculate that levee construction leads to enhanced general resilience or reduced overall system vulnerability. However, given our extensive focus on RFTO in this paper, we are more concerned with the aspects of specified resilience (or robustness) over those of general resilience. Note that the field of resilience thinking distinguishes between general resilience and specified resilience (Folke et al. 2010). General resilience is about coping with a wide range of disturbances, including unexpected ones. Specified resilience, in contrast, is about "resilience of what to what," (Carpenter et al. 2001) and its application requires a clear definition of what is included in the system boundary, what is a system performance of interest that needs to be maintained, and to which set of disturbances the system performance should develop resilience. The case with robustness and RFTO is exactly the same as specified resilience (Anderies et al. 2013). The application of RFTO to the levee effect requires us to (1) be specific about its system boundary (e.g., a polder and communities within it), system performance of interest (e.g., economic outputs), and the disturbances of interest (e.g., flood hazards with different return periods) and (2) focus on how vulnerabilities shift from one frequency range of flood hazard to another range instead of overall system vulnerability to all forms of disturbances.

\section{Background}

The coastal region of southwest Bangladesh is characterized by deltaic floodplains of the Ganges and Brahmaputra rivers. This region is regularly exposed to flood-related natural hazards (Brammer 2010, Auerbach et al. 2015). Before the British colonization in the 18th century, much of the region was forested with little human intervention. People depended on forest resources, inshore fishing, and small-scale agriculture for living. Extensive agriculture was impossible because the area's low-lying lands were exposed to seawater inundation twice a day. With the British colonization, however, major changes to land use and livelihood took place (Ishtiaque et al. 2017). Landlords cleared large tracts of forest lands and leased them for farming. Population size increased and farmers constructed pockets of small earthen levees with the support of landlords. Although the earthen levees provided some protection against saline water intrusion, the region and the communities within it were still exposed to rare floods caused by major weather events, such as tropical cyclones. There was little or no sign of major collective action for flood protection during this period, for instance via voluntary contributions to support large-scale infrastructure.

In the 1960s and 1970s, however, the Bangladesh government initiated the Coastal Embankment Project to suppress flood risk and to increase agricultural productivity in the region. Multilateral agencies supported the project. This project led to the construction of 37 polders in the country's southwest region, encompassing $1556 \mathrm{~km}$ of levees (or embankments) designed to protect low-lying lands from riverine flooding and storm surge (Dewan et al. 2015). A polder is an engineered hydrological unit that surrounds a tract of floodplain enclosed by embankments and sluice gates (Fig. 4A). Embankments protect the area inside
Fig. 4. (a) A conceptual cross-section view of polders. (b-c) A scenario of moderate flood protection level and "living with floods" that allows opportunities for learning. The dynamics of three variables are traced over time under this scenario: peak water surge level (W), embankment height $(\mathrm{K})$, and percentage of cooperators $(\mathrm{X})$. This scenario shows that allowing moderate exposure to flooding can help maintain the community norm for collective action through continuous social learning. (d-e) A scenario of high flood protection level. The dynamics of W, K, and $\mathrm{X}$ under this scenario show that the suppression of hydrological variability and the lost opportunities for social learning can cause the community norm to decay and eventually collapse. Adapted from Yu et al. (2017).
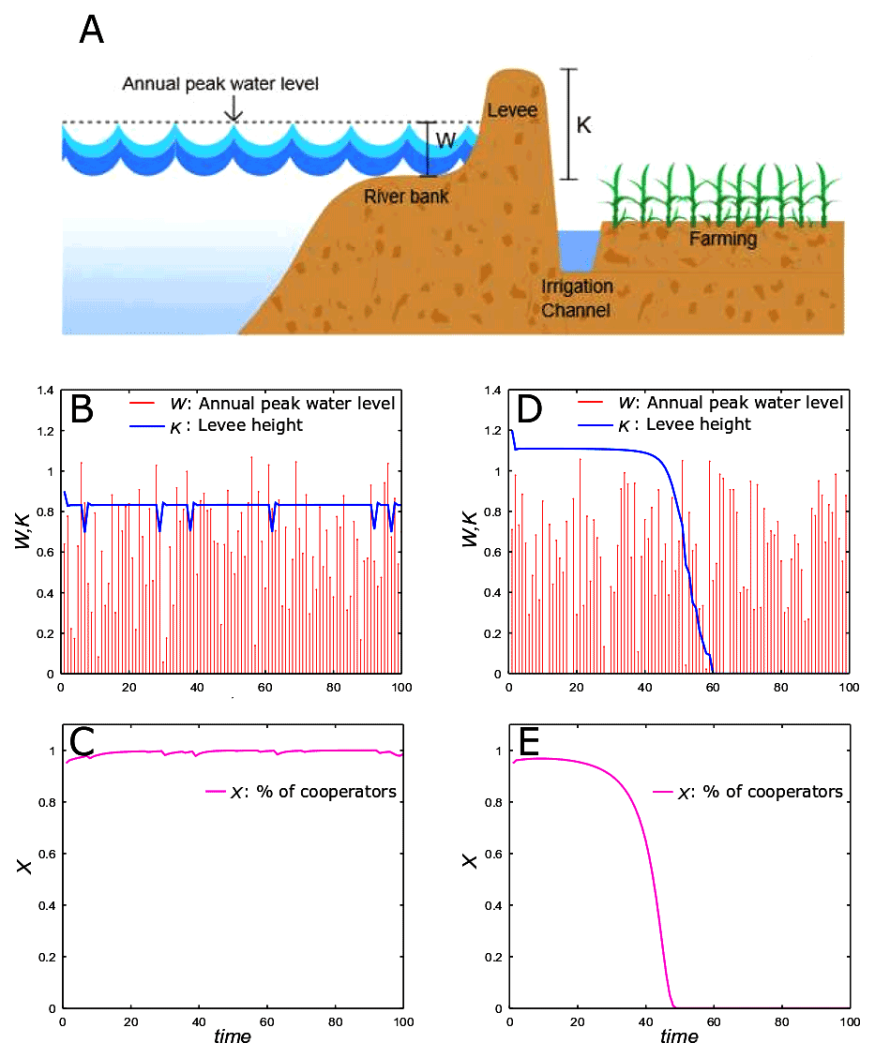

from flooding. Sluice gates are used to exchange water with surrounding bodies of water. Two major changes took place because of the project. First, with the enhanced flood protection, extensive agriculture and aquaculture became widespread (Swapan and Gavin 2011, Amoako Johnson et al. 2016). This led to increased population and increased land use for economic production. Second, the presence of shared polder infrastructure required involvement or collective action of local communities to maintain the infrastructure (Sultana and Thompson 2010, 2017). Because insufficient or delayed support from the central government is common in this region, the local residents have no choice but to initiate effort to engage in such maintenance activities. Collective action tends to occur in two forms: in normal situations, people need to work together periodically to counter the natural erosion of embankments, while in emergency, people must work together to address breakdowns of embankments that 
randomly occur when storm surges hit the coasts. Indeed, local communities tend to have strong social norms, which effectively suppress free riding, for collective maintenance of the polders (Afroz et al. 2016).

The construction of the polders has led to improved protection against more regular floods. However, as indicated by the great losses suffered from the Great Bhola Cyclone of 1970, which included the deaths of more than 250,000 people, the region is still vulnerable to rare but acute floods (Hossain et al. 2008). In fact, because of increased population size and economic activity in the polders, combined with the deteriorating quality of polder infrastructure, the region probably has developed increased fragility to rare floods.

\section{RFTO analysis}

We use the stylized model of collective management of a polder in southwest Bangladesh developed by Yu et al. (2017) to illustrate how RFTO can be used to interpret the levee and adaptation effects. The model was developed to understand critical general features that affect the long-term resilience of coastal communities in the region. Two model elements are key drivers of human-flood interaction in the model system: polder infrastructure and collective action for polder maintenance. Polder infrastructure protects residents from flooding. The level of flood protection provided by embankment height, however, can decline over time through natural erosion or breaches caused by storm surges. The model assumes that the residents share a collective goal to maintain a predetermined level of flood protection through regular maintenance. Individuals can choose from two behavioral strategies about this social goal: contribute to community-organized maintenance work (cooperators) and free-ride without contribution (defectors). In each time step, an individual chooses the strategy that gives a higher expected payoff. Strategy payoff comprises monetary and nonmonetary portions. Monetary payoff is determined by flood damage, agricultural yield, and the cost of polder maintenance. Nonmonetary payoff is determined by the penalty accruing to defectors in the form of social ostracism and the cost of sanctioning borne by cooperators.

Two model processes are especially important here. First, more flood protection is associated with more costly infrastructure maintenance and reduced flood exposure. Second, a lack of exposure to flooding can lead to reduced ostracism of defectors because there is less awareness of flood risk. The conceptual model used in this study captures these social and hydrological processes and shows how outcomes such as agricultural yield and level of collective action (percentage of cooperators) change over time. The model results suggest that allowing some hydrological variability to enter into the polder can increase the community resilience through the preservation of social norm for collective action. More detailed description of the model can be found in the work of Yu et al. (2017).

A set of model outputs illustrates the levee effect in our model simulations. Greater flood protection reduces the occurrence of flooding (which happens when water level is higher than the embankment level) in the early stages of the simulations (Fig. 3D). This signifies enhanced robustness to frequent, regular floods. This success, however, leads to an increase in fragility to the collective action problem of infrastructure maintenance because the defector strategy can more easily spread because of a lack of flood exposure and a higher cost of maintenance (Fig. 4E). As such, when a rarer flood that calls for greater collective action occurs, the model system collapses. In short, there is a trade-off in robustness or conservation of fragility between two time frequencies: frequent floods and rarer floods. The case thus fits the conditions described by RFTO theory. More specifically, based on the RFTO typology shown in Figure 1, the levee effect can be interpreted as a case of structural and feedback RFTO (Fig. 1D), because of the presence of structural modification (embankments) and the associated feedback-driven social actions to maintain the embankment level to a predetermined level. It is worth mentioning that the levee effect is also concordant with a concept in resilience thinking referred to as "specified resilience," which is akin to RFTO. Specified resilience is about "resilience of what to what and for whom" (Carpenter et al. 2001, Lebel et al. 2006). Just as trade-offs in robustness are predicted by RFTO theory, resilience theorists have suggested that enhancing specified resilience to one kind of disturbance regime may often come at the expense of reducing specified resilience to other disturbance regimes (Folke 2016).

RFTO also provides a theoretical grounding for the adaptation effect. A moderate level of flood protection, which occasionally allows flooding, appears to be less robust to flood events and more sensitive to agricultural yields in the early stage of simulations (Fig. 4B). This deliberate allowance of flooding, however, helps to preserve the shared awareness of flood risk and the social norm for collective action within the model community, leading to an increase in robustness to rarer flooding (Fig. 4C). Thus, the notion of the conservation of fragility also applies to this pattern. Because frequent, regular flooding is not overly suppressed in this case, the total amount of fragility is conserved by not amplifying fragility to another disturbance regime, i.e., rarer flooding. In summary, RFTO provides a generalized viewpoint to understanding the levee and adaptation effects, regardless of where they occur or what specific forms of fragility are involved.

\section{CMLS analysis}

CMLS theory provides another lens with which to understand human-flood interactions in southwest Bangladesh. In this region, the hierarchy of social organization is generally divided into three levels: individual, community (polder), and the government. Prior to the Coastal Embankment Project, there was no significant group-level organization at all with regard to practices of flood prevention, so selection among the relevant cultural traits could only have occurred at the level of individuals. At that time, the dominant level of selection was probably the individuals (the first column in Fig. 5). Farmers who did a better job maintaining small-scale levees for their own farmlands would have been more successful, and effective individual-level coping strategies to floods might have spread among farmers via cultural evolution, for example, if farmers imitated other successful farmers. This is an instance of the adaptation effect occurring at the individual level. Even after British colonization, the dominant level of selection remained the same because landlords and farmers still had to manage and build small-scale levees for their own farmlands. Group-beneficial or collective behaviors did not immediately follow colonization. However, continuous floods were a significant problem for landlords and farmers as they looked to cultivate crops on a larger scale. Flood coping activities 
Fig. 5. Likely changes in the level of selection for flood protection practices and policy in the Bangladesh cost (circa 18th century to present). DLS = dominant level of selection (hypothesized). White and black ovals represent social units with different cultural norms for flood protection practices. Braces (\{) represent social dilemmas. Adapted from Hanes and Waring (2018).
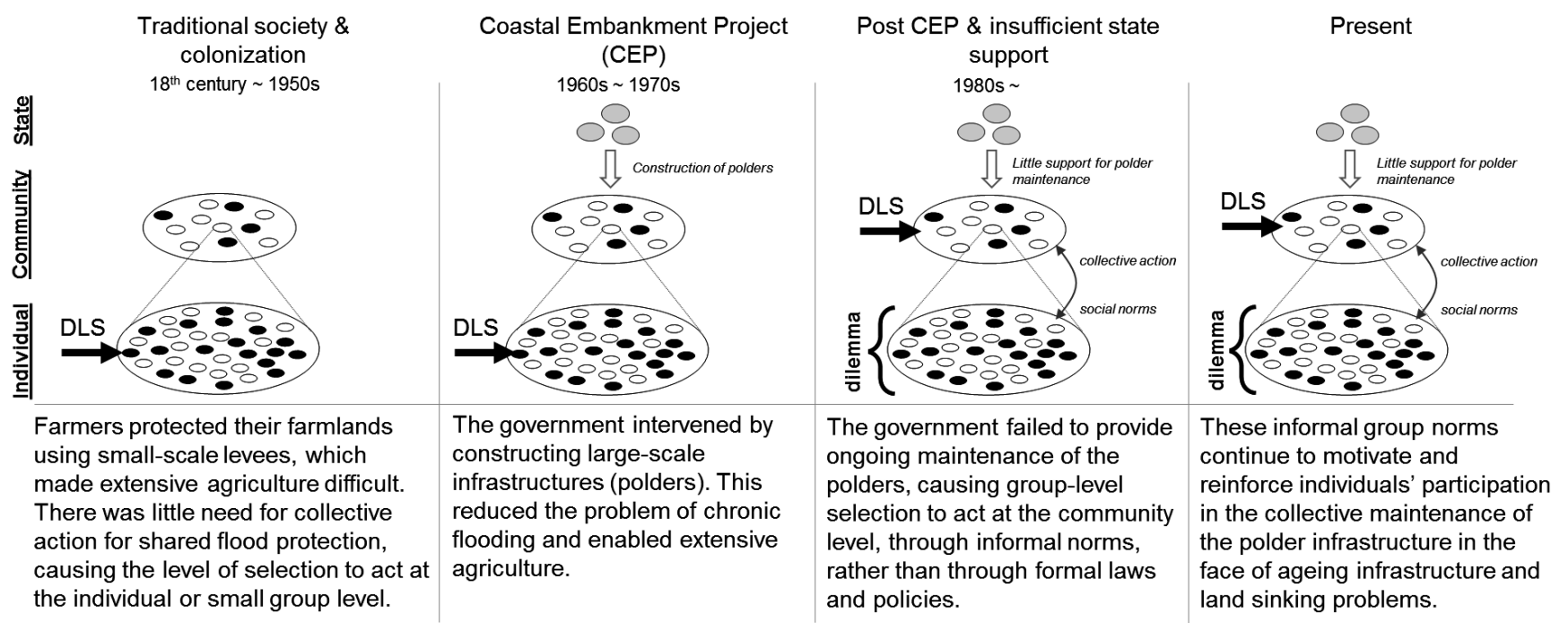

at the level of individuals were not nearly enough to support largescale, extensive agriculture in the low-lying floodplains.

To encourage productivity on a larger scale, and increase cultural fitness of the nation as a whole, the Bangladesh government implemented the Coastal Embankment Project, which constructed embankments (polders) around low-lying lands on floodplains (the second column in Fig. 5). However, a lack of government support for polder maintenance led to selection occurring at the community level (the third column in Fig. 5). In the absence of top-down incentives or enforcement from the government, residents confronted a collective action problem regarding the maintenance of the polders. Individuals who could have spent their time farming, or engaging in other activities that would have been more profitable to them, began to act instead for the group's interest by participating in polder maintenance. As in other cases in which cultural selection is shifted from competition among traits of individuals to traits of groups, culturally learned norms imposed reputation-based costs that countered the benefits of selfish actions (the fourth column in Fig. 5). This enabled residents along the Bangladesh coast to cooperate with their neighbors for the benefit of the community, in spite of the temptation to act for their own individual benefit instead. Simultaneously, effective norms of polder maintenance most likely spread among communities through knowledge transfer, in a form of group-level, success-biased social learning. Both mechanisms provide a plausible pathway through which culturally inherited traits that contribute to flood protection came to be what they are. This is an instance of the adaptation effect occurring at the group level because community adaptive capacity is reinforced through frequent exposure to the collective action problem of polder maintenance, which, if unresolved, threatens people's livelihoods.

Without effective government incentives or enforcement, which restrain the behavioral choices of individuals, social learning and polder maintenance cost per household probably became critical features that enable community sustainability and extensive agriculture. Further, the region is and will be increasingly exposed to flood risks from human-induced sinking of delta lands and extreme weather events. Thus, the coupled human-water systems in the region are at the crossroads of pursuing more techno-centric solutions versus learning to live with floods. The techno-centric approach of continuous levee heightening can lead to a greater decay of flood memory (because of lack of people's exposure to regular floods and lost opportunities for social learning) and an increase in per household cost for polder maintenance. In such cases, the dominant level of selection will likely shift from community to individuals and make collective action difficult. This hypothetical scenario is an instance of the levee effect, i.e., overdependence on the polder infrastructure leading to an erosion of community adaptive capacity.

\section{CHANNELIZATION AND RESTORATION IN THE KISSIMMEE RIVER BASIN, FLORIDA}

In socio-hydrology, the metaphor of a swinging pendulum has been used to conceptualize shifts in a society's preferences for water allocation between emphasizing development and economic gain, on one hand, and environmental protection and restoration, on the other. A key construct used to model such swings is that of "community sensitivity" to environmental health (Elshafei et al. 2015, Mostert 2018). The state of community sensitivity is assumed to be affected by some hydrological event, e.g., flood damages, which in turn feeds back to affect behavioral responses, e.g., building higher levees. Community sensitivity to environmental concerns is decreased when flooding occurs, and as sensitivity becomes progressively lower, a society prefers more development and control of water resources for stability and economic gain. In contrast, when environmental degradation occurs, because of the development and control of water resources, community sensitivity to environmental health is 
increased. Here, we use the case of channelization and restoration in the Kissimmee River Basin to illustrate how RFTO and CMLS can aid our interpretation of such swings in social preference.

\section{Background}

The Kissimmee River Basin lies in central Florida, extending from the south side of Orlando to Lake Okeechobee. This river basin was channelized in the 1960s, as the pendulum swung in the direction of economic development, but the channelization was later reversed in 1990s, as the pendulum swung in the other direction. Here, the upstream and downstream regions are characterized by different social and natural environments. Urban communities are found in the upstream region, and because most urban residents live far away from the river corridor, floods are not a primary issue. In contrast, most of the downstream residents depend on agriculture for their livelihood, and because most of their farmlands are located on floodplains, their livelihoods are sensitive to flooding. Over the past several decades, the population in the upstream region has increased substantially, while the downstream population has increased only slightly (Chen et al. 2016). Hurricanes have periodically caused more agricultural damage in the downstream region. For example, the two consecutive hurricane events of 1947 destroyed much of the agriculture in the downstream area (Koebel 1995). Indeed, this agricultural vulnerability provided the initial impetus for residents to petition the government for hydrological intervention (Chen et al. 2016).

In response to the residents' request, the U.S. government commissioned the U.S. Army Corps of Engineers to initiate the Kissimmee River Channelization Project, which was implemented between 1962 and 1971. This project transformed the natural winding river to a man-made straightened canal that is $90 \mathrm{~km}$ in length. As intended, the channelization effectively reduced flooding in the downstream region by suppressing runoff fluctuations. This success, however, created a new problem: wetland loss in the downstream areas (Toth et al. 1995). The wetlands in the region gradually dried out because water runoff was cut short by the channelized river. The region's wetlands shrunk in size by approximately $120 \mathrm{~km}^{2}$, which equates to about $70 \%$ of the original wetland area. This consequently resulted in a serious loss of biodiversity in the region (Koebel and Bousquin 2014). This destruction of the wetland ecosystem greatly concerned urban residents in the upstream region, who had greater population size, and thus greater political influence than downstream residents. Upstream residents actively voiced their concerns to the government, and sought to reverse the loss of the wetlands, ultimately resulting in the authorization of the Kissimmee River Restoration Act by the federal and state government (Chen et al. 2016).

The restoration project began in 1999 and is expected to be completed by 2020-2021. To minimize the loss of flood control provided by the channels, only the midstream section of channels was removed and returned to its past natural conditions. Simultaneously, lands near the river were bought out by the government and restored to floodplains to provide "room for river." As the floodplains store a great amount of water, this kind of green infrastructure provides a buffer against flood waters, while also restoring the wetland ecosystem. In the final analysis, the restoration project has increased the risk of downstream floods, but this increased risk is estimated to be acceptable for agricultural purposes (Bousquin et al. 2009).

\section{RFTO analysis}

We can use an RFTO lens to identify shifts in system fragility as the region's coupled human-water system went from channelization to restoration of the Kissimmee River Basin. Chen et al. (2016) designed a stylized model of the case to capture the shifts in built infrastructure and their impacts, noting that the channelization project and the restoration project targeted different domains of disturbance. According to RFTO, the coupled system cannot be perfectly robust to all disturbances at different domains. The channelization was done mainly to increase the robustness of agriculture to floods, whereas the restoration project primarily aimed to reduce the vulnerability of biodiversity and wetland ecosystem health to altered hydrological regime. Both structural changes, mainly driven by the conflicting cultural concerns of upstream and downstream residents, can be interpreted as a case of structural RFTO (Fig. 1A). But the resulting changes of hydrological and natural systems are fed back to influence cultural concerns of the residents, resulting in feedback running in both directions between human systems and water systems.

Channelization, the goal of which was to enhance robustness to floods, initially performed well. Reduced flood intensity and variance limited damage to crops of downstream farmers. However, this improvement to hard infrastructure did not eliminate fragility but actually moved it to a different domain (from flooding to loss of biodiversity). Despite robust protection against floods, wetland health problems arose, creating a new threat to the sustainability of the coupled human-water system in the region. The channelization was an adequate solution with regards to flood protection but had an adverse impact with regards to wetland biodiversity. In other words, this is a case of fragility trade-off between two domains: flooding and environmental health. The government and society perceived this emergent vulnerability only after the degradation of the wetlands and thus started a restoration project in the Kissimmee River Basin to recover already diminished wetlands. The restoration project, while still ongoing, has recovered substantial wetland habitat that was destroyed by the channelization. In the course of restoration, however, the government considered both flood protection and the area's ecological health. Although some amount of flood risk is inevitable now in the downstream region, it is limited to an acceptable level. The wetlands, meanwhile, have improved substantially, recovering almost back to the original level. In summary, application of RFTO to the case helps an analyst to think about potential fragility trade-offs across entirely different domains or scales (floods vs. biodiversity), as opposed to across different levels of a scale (frequent vs. rare floods), that arise as a result of structural changes.

\section{CMLS analysis}

Cultural evolution and the CMLS theory help us interpret the multilevel social changes that likely have occurred in the Kissimmee River Basin, which are primarily due to the regional conflict in cultural values between downstream residents, who are less concerned with protecting the environmental, and upstream residents, who are more concerned. Chen et al. (2016) captured these changing norms over time using the lumped variable of 
Fig. 6. Likely changes in the level of selection for social preferences and policy concerning river engineering and management in the Kissimmee River Basin (circa early 20th century to present). DLS = dominant level of selection (hypothesized). White and black ovals represent social units with different cultural norms for flood protection practices. Braces (\{) represent social dilemmas. Adapted from Hanes and Waring (2018).

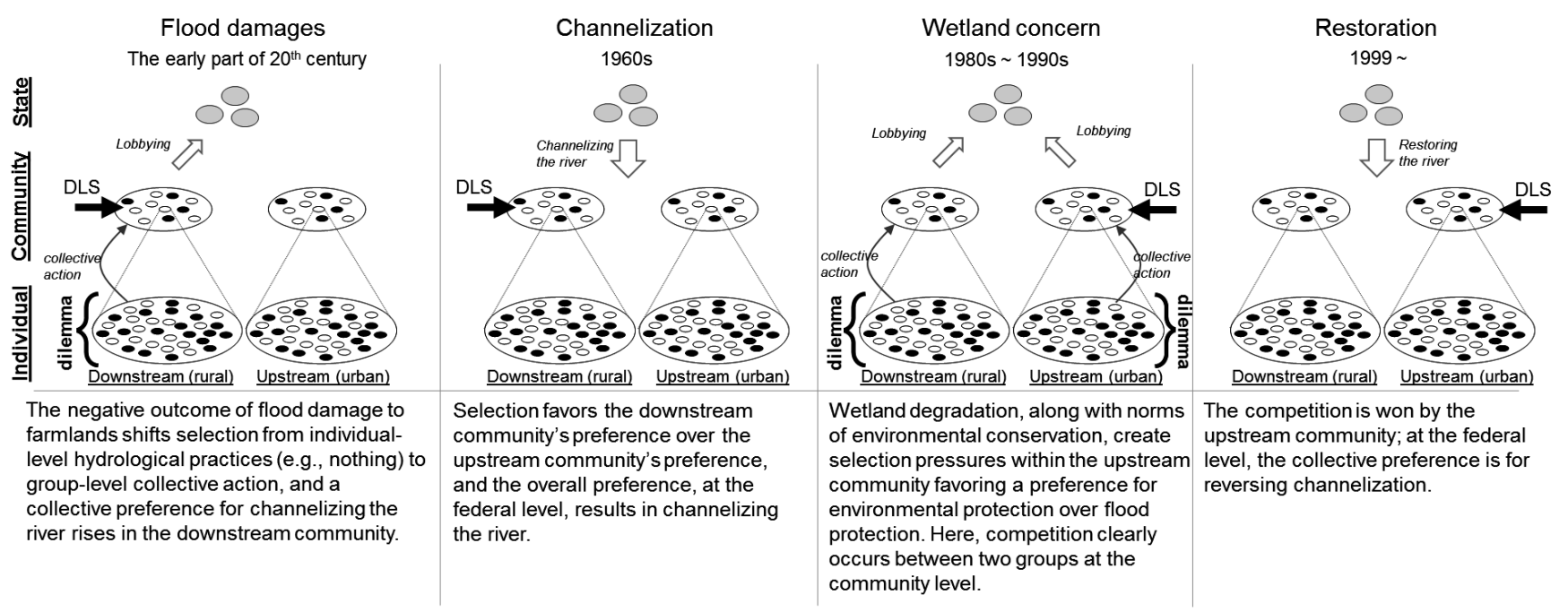

community sensitivity, but CMLS allows us to understand the detailed dynamics driving community sensitivity at multiple levels of social organization, including the individual, community (upstream and downstream), and federal levels.

Downstream residents have historically attempted to protect their farmlands from intensive floods because their crop yields are a direct function of flood damage. Floods thus serve as a powerful source of selection acting on farmers' preferences regarding flood protection. When destructive hurricanes in 1947 devastated crops, concerns about flooding spread rapidly through the population of downstream residents. These regional floods effectively shifted selection to the group level, as individual downstream residents were unable to protect themselves from floods without organizing collective action and making their voice heard to bringing about government intervention (the first column in Fig. 6). Yet at a higher level of organization, the group of downstream residents also had to compete with the group of upstream residents, who were not overly concerned about floods. Initially, downstream residents won this competition, because preferences for wetland conservation had not yet evolved. The overall frequency of preferences in the combined population thus favored increased flood protection, and at the federal level, the group acted to channelize the river (the second column in Fig. 6).

The channelization successfully protected farmlands by decreasing the intensity and variance of floods, but the resulting decline in wetlands likely triggered the emergence of a new set of preferences among upstream residents that spread through the populations via cultural evolution, in virtue of a cultural norm favoring environmental protection that became widespread in the U.S. over 1970s and 1980s. Among upstream communities, this norm-based preference was not constrained by the realities of agricultural flood protection. Downstream farmers, meanwhile, were still worried about flood damage to their farmlands. The level of selection remains at the group level, as both downstream and upstream residents were unable to influence major infrastructure decisions without organizing collective action and making their voice heard to the government. Because of the rapid population growth in the upstream region, however, preferences for wetland protection among upstream residents became more dominant in the general population overall than preferences for flood protection (the third column in Fig. 6). As a result, the downstream group lost the competition with the upstream group, the pendulum swung back in the direction of community sensitivity to the environment, and the government intervened to reverse the previous channelization project (the fourth column in Fig. 6).

In summary, cultural evolution and CMLS theory help an analyst to account for the changing cultural norms over time in the Kissimmee River Basin by illuminating multilevel processes that underlie community sensitivity. Instead of relying on the concept of community sensitivity itself to describe an important social change (e.g., Chen et al. 2016), and thereby abstracting away from processes about why and how the relevant frequencies of individual preferences changed as they did, an analysis based on CMLS is capable of providing causal pathways through which these frequency change, in terms of fundamental principles of cultural selection acting on different types of preferences within groups arising at different levels of social organization. Figure 5 illustrates our analysis, again employing the organizational levels of individual, community (upstream vs. downstream), and federal.

\section{DISCUSSION: COMPLEMENTARITY OF RFTO AND CMLS}

Socio-hydrology, or the study of coupled human-water system, is a rapidly growing field of research with much to be clarified. As such, the field still leaves room for further improvement from more 
perspectives that are theoretical. In particular, we argue that coupled human-water systems are part designed and part selforganized in nature and, thus, are in need of theoretical perspectives that assist our understanding of how the interplay between design and self-organization shapes emergent dynamics. A lack of unifying theoretical frameworks hinders the generalization of results between cases, as has been lamented in the related field of sustainability science (Levin and Clark 2010).

We have shown that theoretical cross-fertilization can overcome the generalizability problem in the coupled human-water systems of southwest Bangladesh and Kissimmee River Basin, Florida. Specifically, we have shown that the theories of RFTO and CMLS already provide excellent conceptual tools for linking and understanding the phenomena of the levee effect and pendulum swing in these two case areas. This generalization exercise has yielded some interesting comparisons. Both areas display significant built infrastructure developments: mega-scale embankments in coastal Bangladesh and the Kissimmee River channelization. Both regions also display a latter change in which built infrastructure is removed (Kissimmee River Basin) or is faced with maintenance problem (coastal Bangladesh). Moreover, both regions display changes in the level of social decision making over time.

More importantly, RFTO and CMLS are complementary, rather than competing, in assisting our understanding of the phenomena. RFTO theory explains how overall system changes, including structural modifications such as the construction of embankments or channels, can generate hidden endogenous risks. Built infrastructure is especially prominent in human-water relationships (Di Baldassarre et al. 2015), and thus important in socio-hydrology. This theory exposes an illusion of robustness from hard infrastructure improvement and can help identify potential dangers for system sustainability. The CMLS theory, meanwhile, concerns how human cultural dynamics can act as an endogenous driver of system change (Waring et al. 2015), a major challenge in theories of sustainability (Caldas et al. 2015). This perspective can strengthen our understanding of how human water management systems evolve. The key predictive mechanism of CMLS theory is that within a hierarchically organized society, the level of social organization at which environmental adaptations will emerge is the level that experiences the strongest evolutionary pressures for environmental management. Because modern societies have a nested structure of social organizations (Gowdy and Krall 2016), this insight is globally applicable. In addition, these two theory sets have one other important commonality: both CMLS and RFTO propose endogenous factors to help explain coupled human-water system dynamics. CMLS explains endogenous cultural adaptation to the environment as a result of social and environmental pressures and RFTO explains endogenous systemic weaknesses that arise as a result of fine-tuning of system designs. We believe that this endogeneity gives each theory extra value in understanding the socio-hydrological phenomena.

Applying two theories has gained us a few key benefits. From an RFTO perspective, structural modifications that seem to enhance the robustness of the present coupled human-water system may also generate concealed fragilities in other domains. When these fragilities are exposed to people, they abruptly bring failures of systems. Linking infrastructure alteration with human-water interactions in an RFTO concept, the theory assists our interpretation of the levee and adaptation effects. On the other hand, CMLS theory provided a way to identify the social factors that drive changes in system management by focusing on forces that enable individuals to act in individual or in the collective interest. For example, when the dominant level of cultural selection changes, we observed that major infrastructure projects were either undertaken or abandoned. Based upon this comparative exercise, we suggest that combining theories to suit a given case study may be an effective way to study and interpret coupled human-water systems. In the case of Bangladesh, for example, the RFTO theory does not sufficiently account for multilevel social processes that shaped infrastructure design choices, but CMLS theory clarifies how social processes, e.g., collective action and social learning, influenced the engineering design choices and system stability after the design implementations. In the case of the Kissimmee River Basin, CMLS provides a more satisfying account of the shifting of people's collective preference for water resources allocation and accompanying social decision making on engineering design by describing how social processes within and between levels in a nested hierarchy evolve in response to changing circumstances. However, CMLS does not clearly delineate how these multilevel social processes might transfer fragilities to other scales or levels within a scale, an aspect that is well addressed by RFTO.

Putting these pieces together, we articulate the current paper's contribution to the field of socio-hydrology. There have been numerous studies that describe and discuss at length the situations and complexities in coastal Bangladesh (Nicholls et al. 2018) and the Kissimmee and the Everglades restoration (Gunderson and Light 2006, Walker and Salt 2006). So there is already a wealth of information about these cases, and the current paper does not add anything new in this regard. The value of our work lies in that previous socio-hydrology studies on this topic have lacked the theoretical foundation to explain why and how particular social changes took place in these cases, a glaring gap from the social sciences perspectives. In Ishtiaque et al. (2017), their treatment of social change in southwest Bangladesh is largely descriptive. In Chen et al. (2016), a social variable called community sensitivity is used to describe and explain the social change that took place in the Kissimmee area. Unfortunately, despite its conceptual simplicity, community sensitivity is a "lumped" concept that provides little detail about the individual-level causal mechanisms driving social change. A cultural trait, e.g., norms, beliefs, values, etc., within a community is assumed to change mechanistically in reaction to external stimuli, and is associated with a deterministic behavioral response based on its current state. In fact, a similar approach is used by other existing socio-hydrology studies (e.g., Di Baldassarre et al. 2013, Van Emmerik et al. 2014). Therefore, the contribution of our work is as follows. It formally introduces CMLS to the socio-hydrology literature, a solid conceptual tool based on the broader theory of cultural evolution capable of explaining social change (Richerson and Boyd 2004). It then applies CMLS to the two cases to illustrate the general mechanisms of causation that can explain the observed social changes. It then goes further by highlighting RFTO and illustrating how CMLS and RFTO can be used in tandem to interpret changes in coupled human-water systems. This combined use of RFTO and CMLS adds a value because social change usually occurs in response to 
internal stresses and pressures from outside (e.g., Ostrom 2014). RFTO provides a way to think about how such stresses and pressures play out and cause trade-offs in fragility as human systems make efforts to enhance robustness and performance in particular ways. In this way, RFTO and CMLS are complementary and their combined use helps us examine how multiple socio-hydrologic phenomena can be tied together and explained using an overarching theoretical framework.

Last, while appreciating the insights above, one should not lose sight of the fact that one of the key goals of socio-hydrology is to be a "use inspired" science. In other words, the community aims to develop fundamental understanding that can be applied to design or management of water resources systems. How can the application of RTFO and CMLS be a good step in this direction? How can the use of RFTO and CMLS to interpret the mechanisms generating phenomena such as the pendulum swing or the levee effect contribute to the use-inspired aspiration of socio-hydrology? Our answer is that the combined use of RFTO and CMLS facilitates the understanding of water resources systems as a complex adaptive system, a view that emphasizes holistic (rather than reductionist) approaches to a problem (Levin 1998, Holland 2006). This is important to design or management of water resources systems because complex adaptive systems thinking in the mental models of key actors involved in decision making is thought to generally reduce the probability of myopic decisions and, thus, unintended consequences in the long run (Biggs et al. 2012, Yu et al. 2020). RFTO and CMLS help in this regard by forcing analysts to pay attention to slow variables and feedbacks, potential trade-offs in vulnerability stemming from system modifications, and long-term social change arising from social learning and cross-level interactions within a social hierarchy. As such, the combined use of RFTO and CMLS can influence management choices in ways that are mindful of such complexities.

\section{CONCLUSIONS}

Socio-hydrology is a special case of social-ecological systems research with an explicit focus on water and coupled human-water system dynamics. Although coupled human-water systems tend to contain both designed and self-organized components, theoretical frameworks that assist our understanding of the interplay between design and self-organization have been elusive. We argue that this is particularly the case for emergent trade-offs in system fragility that arise because of design choices and how social processes within and between the levels of organizational hierarchy influence and are influenced by such design choices. Thus, our goal here has been to contribute to addressing this gap by applying and developing insights on how the theoretical frameworks of robustness-fragility trade-off (RFTO) and cultural multilevel selection (CMLS) can be effective in this regard. We have done so by showing how RFTO and CMLS can be applied to the levee effect and the pendulum swing cases in southwest Bangladesh and central Florida, respectively. These theories bring much needed social science richness into the sociohydrology literature, one that has historically been dominated by physical science and engineering perspectives. Indeed, the socialecological literature and the socio-hydrology literature have many common goals, and it is only recently that the fields have started substantial exchanges. Thus, another goal of this paper is to play a role in filling that gap.
A single theory is limited in its demonstration of the complex nature of coupled human-water systems, but combined, theories such as RFTO and CMLS can complement each other, connecting discontinuous stories and enriching the field of sociohydrology with generalized interpretations. In this way, we will be able to better identify and analyze causal relationships of historical events involved with water issues. This is not to say that place-based studies are less important. By reflecting the unique contexts of a place and its water history, place-based studies of coupled human-water systems can be valuable for generating rich context-specific understanding. However, from a long-term, systems thinking perspective, we argue that such place-based studies often exhibit recurring features that call for generalization. Combining general theories that address the part designed and part self-organized nature of coupled human-water systems can be effective in illuminating such common aspects across different place-based studies. Furthermore, generalized information from combined theories will not only broaden our insight into humanwater coevolution of the past but also help us cope with water sustainability crises in the future. Generalization from theories in combination can facilitate a more comprehensive analysis with long-term systems perspectives for the future of water management. That is, it will be possible for policy makers to grasp complex interrelations among human behavior, water resources, governance arrangements, and built infrastructure, guided by synergistic insights from combined theories. This will help them implement policies and engineering designs that contribute toward water security and sustainability in the long run.

Responses to this article can be read online at: http://www.ecologyandsociety.org/issues/responses. php/11887

\section{Acknowledgments:}

The authors thank the National Science Foundation (CIS-1913665) and the Center for the Environment at Purdue University (C4E seed grant program) for financial support of this research. The authors also thank anonymous reviewers for their comments and suggestions.

Data Availability:

Datalcode sharing is not applicable to this article because no new datalcode were created or analyzed in this study.

\section{LITERATURE CITED}

Afroz, S., R. Cramb, and C. Grunbuhel. 2016. Collective management of water resources in coastal Bangladesh: formal and substantive approaches. Human Ecology 44(1):17-31. https:// doi.org/10.1007/s10745-016-9809-x

Amoako Johnson, F., C. W. Hutton, D. Hornby, A. N. Lázár, and A. Mukhopadhyay. 2016. Is shrimp farming a successful adaptation to salinity intrusion? A geospatial associative analysis of poverty in the populous Ganges-Brahmaputra-Meghna Delta of Bangladesh. Sustainability Science 11(3):423-439. https://doi. org/10.1007/s11625-016-0356-6 
Anderies, J. M. 2015. Managing variance: key policy challenges for the Anthropocene. Proceedings of the National Academy of Sciences 112(47):14402-14403. https://doi.org/10.1073/pnas.1519071112

Anderies, J. M., C. Folke, B. Walker, and E. Ostrom. 2013. Aligning key concepts for global change policy: robustness, resilience, and sustainability. Ecology and Society 18(2):8. https:// doi.org/10.5751/ES-05178-180208

Auerbach, L. W., S. L. Goodbred Jr, D. R. Mondal, C. A. Wilson, K. R. Ahmed, K. Roy, M. S. Steckler, C. Small, J. M. Gilligan, and B. A. Ackerly. 2015. Flood risk of natural and embanked landscapes on the Ganges-Brahmaputra tidal delta plain. Nature Climate Change 5(2):153-157. https://doi.org/10.1038/nclimate2472

Biggs, R., M. Schlüter, D. Biggs, E. L. Bohensky, S. BurnSilver, G. Cundill, V. Dakos, T. M. Daw, L. S. Evans, K. Kotschy, A. M. Leitch, C. Meek, A. Quinlan, C. Raudsepp-Hearne, M. D. Robards, M. L. Schoon, L. Schultz, and P. C. West. 2012. Toward principles for enhancing the resilience of ecosystem services. Annual Review of Environment and Resources 37(1):421-448. https://doi.org/10.1146/annurev-environ-051211-123836

Bode, H. W. 1945. Network analysis and feedback amplifier design. Van Nostrand, Princeton, New Jersey, USA.

Bousquin, S. G., D. H. Anderson, M. D. Cheek, D. J. Colangelo, L. Dirk, J. L. Glen, B. L. Jones, J. W. Koebel Jr., J. A. Mossa, and J. Valdes. 2009. Kissimmee Basin. Chapter 11 in South Florida Environmental Report 2009, Volume I. South Florida Water Management District, West Palm Beach, Florida, USA.

Boyd, R., and P. J. Richerson. 1985. Culture and the evolutionary process. University of Chicago Press, Chicago, Illinois, USA.

Brammer, H. 2010. After the Bangladesh Flood Action Plan: looking to the future. Environmental Hazards 9:118-130. https:// doi.org/10.3763/ehaz.2010.SI01

Brooks, J. S., T. M. Waring, M. Borgerhoff Mulder, and P. J. Richerson. 2018. Applying cultural evolution to sustainability challenges: an introduction to the special issue. Sustainability Science 13:1-8. https://doi.org/10.1007/s11625-017-0516-3

Caldas, M. M., M. R. Sanderson, M. Mather, M. D. Daniels, J. S. Bergtold, J. Aistrup, J. L. Heier Stamm, D. Haukos, K. DouglasMankin, A. Y. Sheshukov, and D. Lopez-Carr. 2015. Opinion: endogenizing culture in sustainability science research and policy. Proceedings of the National Academy of Sciences 112 (27):8157-8159. https://doi.org/10.1073/pnas.1510010112

Carpenter, S., B. Walker, J. M. Anderies, and N. Abel. 2001. From metaphor to measurement: resilience of what to what? Ecosystems 4(8):765-781. https://doi.org/10.1007/s10021-001-0045-9

Chen, X., D. Wang, F. Tian, and M. Sivapalan. 2016. From channelization to restoration: sociohydrologic modeling with changing community preferences in the Kissimmee River Basin, Florida. Water Resources Research 51(2):1227-1244. https://doi. org/10.1002/2015WR018194

Chudek, M., W. Zhao, and J. Henrich. 2013. Culture-gene coevolution, large-scale cooperation, and the shaping of human social psychology. Pages 425-458 in K. Sterelny, R. Joyce, B. Calcott, and B. Fraser, editors. Cooperation and its evolution. MIT Press, Cambridge, Massachusetts, USA. https://doi.org/10.7551/ mitpress/9033.003.0024
Csete, M. E., and J. C. Doyle. 2002. Reverse engineering of biological complexity. Science 295(5560):1664-1669. https://doi. org/10.1126/science.1069981

Dewan, C., A. Mukherji, and M.-C. Buisson. 2015. Evolution of water management in coastal Bangladesh: from temporary earthen embankments to depoliticized community-managed polders. Water International 40(3):401-416. https://doi. org/10.1080/02508060.2015.1025196

Di Baldassarre, G., F. Martinez, Z. Kalantari, and A. Viglione. 2017. Drought and flood in the Anthropocene: feedback mechanisms in reservoir operation. Earth System Dynamics 8 (1):225-233. https://doi.org/10.5194/esd-8-225-2017

Di Baldassarre, G., M. Sivapalan, M. Rusca, C. Cudennec, M. Garcia, H. Kreibich, M. Konar, E. Mondino, J. Mård, S. Pande, M. R. Sanderson, F. Tian, A. Viglione, J. Wei, Y. Wei, D. J. Yu, V. Srinivasan, and G. Blöschl. 2019. Sociohydrology: scientific challenges in addressing the sustainable development goals. Water Resources Research 55(8):6327-6355. https://doi. org/10.1029/2018WR023901

Di Baldassarre, G., A. Viglione, G. Carr, L. Kuil, J. L. Salinas, and G. Blöschl. 2013. Socio-hydrology: conceptualising humanflood interactions. Hydrology and Earth System Sciences 17 (8):3295-3303. https://doi.org/10.5194/hess-17-3295-2013

Di Baldassarre, G., A. Viglione, G. Carr, L. Kuil, K. Yan, L. Brandimarte, and G. Blöschl. 2015. Debates-perspectives on socio-hydrology: capturing feedbacks between physical and social processes. Water Resources Research 51(6):4770-4781. https://doi. org/10.1002/2014WR016416

Di Baldassarre, G., N. Wanders, A. AghaKouchak, L. Kuil, S. Rangecroft, T. I. E. Veldkamp, M. Garcia, P. R. van Oel, K. Breinl, and A. F. Van Loon. 2018. Water shortages worsened by reservoir effects. Nature Sustainability 1(11):617-622. https://doi. org/10.1038/s41893-018-0159-0

Ellis, E. C., N. R. Magliocca, C. J. Stevens, and D. Q. Fuller. 2018. Evolving the Anthropocene: linking multi-level selection with long-term social-ecological change. Sustainability Science 13 (1):119-128. https://doi.org/10.1007/s11625-017-0513-6

Elshafei, Y., J. Z. Coletti, M. Sivapalan, and M. R. Hipsey. 2015. A model of the socio-hydrologic dynamics in a semiarid catchment: isolating feedbacks in the coupled human-hydrology system. Water Resources Research 51(8):6442-6471. https://doi. org/10.1002/2015WR017048

Elshafei, Y., M. Sivapalan, M. Tonts, and M. R. Hipsey. 2014. A prototype framework for models of socio-hydrology: identification of key feedback loops and parameterisation approach. Hydrology and Earth System Sciences 18(6):2141-2166. https://doi.org/10.5194/hess-18-2141-2014

Folke, C. 2016. Resilience (Republished). Ecology and Society 21 (4):44. https://doi.org/10.5751/ES-09088-210444

Folke, C., S. R. Carpenter, B. Walker, M. Scheffer, T. Chapin, and J. Rockström. 2010. Resilience thinking: integrating resilience, adaptability and transformability. Ecology and Society 15(4):20. https://doi.org/10.5751/ES-03610-150420

Georgic, W. 2019. Vulnerability and policy response: unintended consequences. Dissertation. Ohio State University, Columbus, Ohio, USA. 
Gober, P., and H. S. Wheater. 2015. Debates - perspectives on socio-hydrology: modeling flood risk as a public policy problem. Water Resources Research 51(6):4782-4788. https://doi. org/10.1002/2015WR016945

Gowdy, J., and L. Krall. 2016. The economic origins of ultrasociality. Brain and Behavioral Sciences 39:e92. https://doi. org/10.1017/S0140525X1500059X

Grafton, R. Q., J. Williams, C. J. Perry, F. Molle, C. Ringler, P. Steduto, B. Udall, S. A. Wheeler, Y. Wang, D. Garrick, and R. G. Allen. 2018. The paradox of irrigation efficiency. Science 361 (6404):748-750. https://doi.org/10.1126/science.aat9314

Gunderson, L., B. A. Cosens, B. C. Chaffin, C. A. (T.) Arnold, A. K. Fremier, A. S. Garmestani, R. K. Craig, H. Gosnell, H. E. Birge, C. R. Allen, M. H. Benson, R. R. Morrison, M. C. Stone, J. A. Hamm, K. Nemec, E. Schlager, and D. Llewellyn. 2017. Regime shifts and panarchies in regional scale social-ecological water systems. Ecology and Society 22(1):31. https://doi. org/10.5751/ES-08879-220131

Gunderson, L., and S. S. Light. 2006. Adaptive management and adaptive governance in the Everglades ecosystem. Policy Sciences 39(4):323-334. https://doi.org/10.1007/s11077-006-9027-2

Hanes, S. P., and T. M. Waring. 2018. Cultural evolution and US agricultural institutions: a historical case study of Maine's blueberry industry. Sustainability Science 13(1):49-58. https://doi. org/10.1007/s11625-017-0508-3

Holland, J. H. 2006. Studying complex adaptive systems. Journal of Systems Science and Complexity 19(1):1-8. https://doi. org/10.1007/s11424-006-0001-Z

Hossain, M. Z., M. T. Islam, T. Sakai, and M. Ishida. 2008. Impact of tropical cyclones on rural infrastructures in Bangladesh. Agricultural Engineering International: CIGR Journal X(2):1-13.

Hutton, N. S., G. A. Tobin, and B. E. Montz. 2019. The levee effect revisited: processes and policies enabling development in Yuba County, California. Journal of Flood Risk Management 12 (3):e12469. https://doi.org/10.1111/jfr3.12469

Ishtiaque, A., N. Sangwan, and D. J. Yu. 2017. Robust-yet-fragile nature of partly engineered social-ecological systems: a case study of coastal Bangladesh. Ecology And Society 22(3):5. https://doi. org/10.5751/ES-09186-220305

Kandasamy, J., D. Sounthararajah, P. Sivabalan, A. Chanan, S. Vigneswaran, and M. Sivapalan. 2014. Socio-hydrologic drivers of the pendulum swing between agricultural development and environmental health: a case study from Murrumbidgee River basin, Australia. Hydrology and Earth System Sciences 18 (3):1027-1041. https://doi.org/10.5194/hess-18-1027-2014

Koebel, J. W. 1995. An historical perspective on the Kissimmee River Restoration Project. Restoration Ecology 3(3):149-159. https://doi.org/10.1111/j.1526-100X.1995.tb00167.X

Koebel, J. W., and S. G. Bousquin. 2014. The Kissimmee River restoration project and evaluation program, Florida, USA. Restoration Ecology 22(3):345-352. https://doi.org/10.1111/ rec. 12063

Konar, M., M. Garcia, M. R. Sanderson, D. J. Yu, and M. Sivapalan. 2019. Expanding the scope and foundation of sociohydrology as the science of coupled human-water systems. Water Resources Research 55(2):874-887. https://doi. org/10.1029/2018WR024088

Lebel, L., J. M. Anderies, B. Campbell, C. Folke, S. HatfieldDodds, T. P. Hughes, and J. Wilson. 2006. Governance and the capacity to manage resilience in regional social-ecological systems. Ecology and Society 11(1):19. https://doi.org/10.5751/ ES-01606-110119

Levin, S. A. 1998. Ecosystems and the biosphere as complex adaptive systems. Ecosystems 1:431-436. https://doi.org/10.1007/ $\underline{\mathbf{s} 100219900037}$

Levin, S. A., and W. C. Clark, editors. 2010. Toward a science of sustainability. Center for International Development Working Papers 196. John F. Kennedy School of Government, Harvard University, Cambridge, Massachusetts, USA.

Liao, K. 2012. A theory on urban resilience to floods - a basis for alternative planning practices. Ecology and Society 17(4):48. https://doi.org/10.5751/ES-05231-170448

Loucks, D. P. 2015. Debates-perspectives on socio-hydrology: simulating hydrologic-human interactions. Water Resources Research 51(6):4789-4794. https://doi.org/10.1002/2015WR017002

Martins, N. C., M. A. Dahleh, and J. C. Doyle. 2005. Fundamental limitations of disturbance attenuation in the presence of side information. In Proceedings of the 44th IEEE Conference on Decision and Control, and the European Control Conference, CDC$E C C^{\prime}$ '05. The Institute of Electrical and Electronics Engineers, Piscataway, New Jersey, USA. https://doi.org/10.1109/CDC.2005.1582542

Merz, B., S. Vorogushyn, U. Lall, A. Viglione, and G. Blöschl. 2015. Charting unknown waters-on the role of surprise in flood risk assessment and management. Water Resources Research 51 (8):6399-6416. https://doi.org/10.1002/2015WR017464

Mesoudi, A., A. Whiten, and K. N. N. Laland. 2006. Towards a unified science of cultural evolution. Behavioral and Brain Sciences 29(4):329-347. https://doi.org/10.1017/S0140525X06009083

Montanari, A., G. Young, H. H. G. Savenije, D. Hughes, T. Wagener, L. L. Ren, D. Koutsoyiannis, C. Cudennec, E. Toth, S. Grimaldi, G. Blöschl, M. Sivapalan, K. Beven, H. Gupta, M. Hipsey, B. Schaefli, B. Arheimer, E. Boegh, S. J. Schymanski, G. Di Baldassarre, B. Yu, P. Hubert, Y. Huang, A. Schumann, D. A. Post, V. Srinivasan, C. Harman, S. Thompson, M. Rogger, A. Viglione, H. McMillan, G. Characklis, Z. Pang, and V. Belyaev. 2013. "Panta Rhei-Everything Flows": change in hydrology and society-the IAHS scientific decade 2013-2022. Hydrological Sciences Journal 58(6):1256-1275. https://doi.org/10.1080/02626$\underline{667.2013 .809088}$

Montz, B. E., and G. A. Tobin. 2008. Livin' large with levees: lessons learned and lost. Natural Hazards Review 9(3):150-157. https://doi.org/10.1061/(ASCE)1527-6988(2008)9:3(150)

Mostert, E. 2018. An alternative approach for socio-hydrology: case study research. Hydrology and Earth System Sciences 22 (1):317-329. https://doi.org/10.5194/hess-22-317-2018

Nicholls, R. J., C. W. Hutton, W. N. Adger, S. E. Hanson, M. M. Rahman, and M. Salehin. 2018. Ecosystem services for well-being in deltas: integrated assessment for policy analysis. Springer, Cham, Switzerland. https://doi.org/10.1007/978-3-319-71093-8 
Ostrom, E. 1990. Governing the commons: the evolution of institutions for collective action. Cambridge University Press, Cambridge, UK.

Ostrom, E. 2014. Do institutions for collective action evolve? Journal of Bioeconomics 16(1):3-30.

Reyes-García, V., A. L. Balbo, E. Gómez-Baggethun, M. Gueze, A. Mesoudi, P. J. Richerson, X. Rubio-Campillo, I. Ruiz-Mallén, and S. Shennan. 2016. Multilevel processes and cultural adaptation: examples from past and present small-scale societies. Ecology and Society 21(4):2. https://doi.org/10.5751/ES-08561-210402

Richerson, P., R. Baldini, A. Bell, K. Demps, K. Frost, V. Hillis, S. Mathew, E. Newton, N. Narr, L. Newson, C. Ross, P. Smaldino, T. Waring, and M. Zefferman. 2016. Cultural group selection plays an essential role in explaining human cooperation: a sketch of the evidence. Behavioral and Brain Sciences 39:e30. https://doi. org/10.1017/S0140525X1400106X

Richerson, P. J., and R. Boyd. 2004. Not by genes alone: how culture transformed human evolution. University of Chicago Press, Chicago, Illinois, USA. https://doi.org/10.7208/chicago/9780226712130.001 .0001

Roobavannan, M., T. H. M. van Emmerik, Y. Elshafei, J. Kandasamy, M. Sanderson, S. Vigneswaran, S. Pande, and M. Sivapalan. 2018. Norms and values in socio-hydrological models. Hydrology and Earth System Sciences 22:1337-1349. https://doi. org/10.5194/hess-22-1337-2018

Sanderson, M. R., J. S. Bergtold, J. L. Heier Stamm, M. M. Caldas, and S. M. Ramsey. 2017. Bringing the "social" into sociohydrology: conservation policy support in the Central Great Plains of Kansas, USA. Water Resources Research 53 (8):6725-6743. https://doi.org/10.1002/2017WR020659

Scott, C. A. 2011. The water-energy-climate nexus: resources and policy outlook for aquifers in Mexico. Water Resources Research 47(6). https://doi.org/10.1029/2011WR010805

Sivapalan, M., H. H. G. Savenije, and G. Blöschl. 2012. Sociohydrology: a new science of people and water. Hydrological Processes 26(8):1270-1276. https://doi.org/10.1002/hyp.8426

Srinivasan, V. 2015. Reimagining the past - use of counterfactual trajectories in socio-hydrological modelling: the case of Chennai, India. Hydrology and Earth System Sciences 19(2):785-801. https://doi.org/10.5194/hess-19-785-2015

Stavins, B. R. N., and A. B. Jaffe. 1990. Unintended impacts of public investments on private decisions: the depletion of forested wetlands. American Economic Review 80(3):337-352.

Sultana, P., and P. M. Thompson. 2010. Local institutions for floodplain management in Bangladesh and the influence of the Flood Action Plan. Environmental Hazards 9(1):26-42. https:// doi.org/10.3763/ehaz.2010.SI05

Sultana, P., and P. M. Thompson. 2017. Adaptation or conflict? Responses to climate change in water management in Bangladesh. Environmental Science and Policy 78:149-156. https://doi. org/10.1016/j.envsci.2017.09.011

Sung, K., H. Jeong, N. Sangwan, and D. J. Yu. 2018. Effects of flood control strategies on flood resilience under sociohydrological disturbances. Water Resources Research 54(4):2661-2680. https:// doi.org/10.1002/2017WR021440

Swapan, M. S. H., and M. Gavin. 2011. A desert in the delta: participatory assessment of changing livelihoods induced by commercial shrimp farming in southwest Bangladesh. Ocean \& Coastal Management 54(1):45-54. https://doi.org/10.1016/j. ocecoaman.2010.10.011

Tellman, B., J. C. Bausch, H. Eakin, J. M. Anderies, M. MazariHiriart, D. Manuel-Navarrete, and C. L. Redman. 2018. Adaptive pathways and coupled infrastructure: seven centuries of adaptation to water risk and the production of vulnerability in Mexico City. Ecology and Society 23(1):1. https://doi.org/10.5751/ ES-09712-230101

Tobin, G. A. 1995. The levee love affair: a stormy relationship? Journal of the American Water Resources Association 31 (3):359-367. https://doi.org/10.1111/j.1752-1688.1995.tb04025.X

Toth, L., A. Arrington, M. Brady, and D. Muszick. 1995. Conceptual evaluation of factors potentially affecting restoration of habitat structure within the channelized Kissimmee River ecosystem. Restoration Ecology 3(3):160-180. https://doi. org/10.1111/j.1526-100X.1995.tb00168.X

Troy, T. J., M. Konar, V. Srinivasan, and S. Thompson. 2015. Moving sociohydrology forward: a synthesis across studies. Hydrology and Earth System Sciences 19(8):3667-3679. https:// doi.org/10.5194/hess-19-3667-2015

Van Emmerik, T. H. M., Z. Li, M. Sivapalan, S. Pande, J. Kandasamy, H. H. G. Savenije, A. Chanan, and S. Vigneswaran. 2014. Socio-hydrologic modeling to understand and mediate the competition for water between agriculture development and environmental health: Murrumbidgee River basin, Australia. Hydrology and Earth System Sciences 18(10):4239-4259. https:// doi.org/10.5194/hess-18-4239-2014

Viglione, A., G. Di Baldassarre, L. Brandimarte, L. Kuil, G. Carr, J. L. Salinas, A. Scolobig, and G. Blöschl. 2014. Insights from socio-hydrology modelling on dealing with flood risk - roles of collective memory, risk-taking attitude and trust. Journal of Hydrology 518:71-82. https://doi.org/10.1016/j.jhydrol.2014.01.018

Walker, B. H., and D. Salt. 2006. Resilience thinking: sustaining ecosystems and people in a changing world. Island, Washington, D.C., USA.

Waring, T. M., M. A. Kline, J. S. Brooks, S. H. Goff, J. Gowdy, M. A. Janssen, P. E. Smaldino, and J. Jacquet. 2015. A multilevel evolutionary framework for sustainability analysis. Ecology and Society 20(2):34. https://doi.org/10.5751/ES-07634-200234

White, G. 1945. Human adjustment to floods. Geography, Resources and Environment 5:10-25.

Wilson, D. S., and K. M. Kniffin. 1999. Multilevel selection and the social transmission of behavior. Human Nature 10(3):291-310. https://doi.org/10.1007/s12110-999-1005-x

Wilson, D. S., E. Ostrom, and M. E. Cox. 2013. Generalizing the core design principles for the efficacy of groups. Journal of Economic Behavior and Organization 90:S21-S32. https://doi. org/10.1016/j.jebo.2012.12.010 
Yu, D. J., M. R. Qubbaj, R. Muneepeerakul, J. M. Anderies, and R. M. Aggarwal. 2015. Effect of infrastructure design on commons dilemmas in social-ecological system dynamics. Proceedings of the National Academy of Sciences 112 (43):13207-13212. https://doi.org/10.1073/pnas.1410688112

Yu, D. J., N. Sangwan, K. Sung, X. Chen, and V. Merwade. 2017. Incorporating institutions and collective action into a sociohydrological model of flood resilience. Water Resources Research 53(2):1336-1353. https://doi.org/10.1002/2016WR019746

Yu, D. J., M. L. Schoon, J. K. Hawes, S. Lee, J. Park, P. S. C. Rao, L. K. Siebeneck, and S. V. Ukkusuri. 2020. Toward general principles for resilience engineering. Risk Analysis 40 (8):1509-1537. https://doi.org/10.1111/risa.13494

Zhang, Z., H. Hu, F. Tian, X. Yao, and M. Sivapalan. 2014. Groundwater dynamics under water-saving irrigation and implications for sustainable water management in an oasis: Tarim River basin of western China. Hydrology and Earth System Sciences 18(10):3951-3967. https://doi.org/10.5194/hess-18-3951-2014 